ARTIGO N³

INFRAESTRUTURA VERDE DA CIDADE DE SALTO PARA O ROTEIRO DOS BANDEIRANTES

GREEN INFRASTRUCTURE OF SALTO CITY FOR THE

ROTEIRO DOS BANDEIRANTES

Sandra SchaAf Benfica | Tatiana Regina da Silva Simão 


\title{
INFRAESTRUTURA VERDE DA CIDADE DE SALTO PARA O ROTEIRO DOS BANDEIRANTES
}

\author{
SANDRA SCHAAF BENFICA* \\ *Arquiteta e Urbanista pela FAU-USP. Certificada pelo PMI em Gerenciamento de Projetos. Arquiteta \\ autônoma pela STC Tecnologia e Consultoria Ltda. \\ sandra.schaaf@stctecno.com.br \\ Tatiana Regina da Silva Simão** \\ **Tecnóloga em edifícios pela FATEC-SP e Mestre em Habitação pelo IPT. Hoje trabalha como pro- \\ fessora do IFSP na área de Construção Civil e no Centro Universitário Belas Artes de São Paulo no \\ Curso de Design de Interiores. \\ simao.tatiana@gmail.com
}

\section{RESUMO}

Este artigo está baseado em estudos e pesquisas realizadas para o desenvolvimento de um trabalho para a Disciplina de Projeto Sustentável do Programa de Pós-Graduação da Faculdade de Arquitetura e Urbanismo da Universidade de São Paulo, trabalho este voltado para a Infraestrutura Verde do Roteiro dos Bandeirantes. O Roteiro dos Bandeirantes faz parte do programa nacional de turismo pela sua importância histórica que levou à ocupação do interior paulista, que teve seu início no começo no século XVI. A região está localizada em uma zona de transição entre o Planalto Atlântico e a Depressão Periférica, região de valor cênico e alto potencial eco turístico. De acordo com as pesquisas realizadas especificamente para a cidade de Salto, o artigo se propõe a analisar a cidade baseando-se nos critérios dos selos Verde e Azul da Secretaria Estadual do Meio Ambiente e do Selo LAB Verde da Universidade de São Paulo. Além disso, pretende-se propor adequações para evidenciar e valorizar o Roteiro dos Bandeirantes na região, integrando-o à cidade também com a finalidade de torná-la mais resiliente e sustentável.

Palavras-chave: Infraestrutura Verde, Hortas Comunitárias, Roteiro dos Bandeirantes, Sustentabilidade e Cidade Resiliente. 


\title{
GREEN INFRASTRUCTURE OF SALTO CITY FOR THE ROTEIRO DOS BANDEIRANTES ${ }^{1}$
}

\begin{abstract}
This article is based on surveys and researches performed for the development of a work for the Subject Sustainable Design of the Program of Post-graduation of the School of Architecture and Urbanism of the University of São Paulo. It focus the Green Infrastructure of the Roteiro dos Bandeirantes ${ }^{1}$ (Bandeirantes' Route). Due to its historical importance this Route takes part of the National Tourism Program and led to the occupation of São Paulo State countryside, which began during early 16th Century. That region is located in a transition zone between the Atlantic Plateau and the Peripheral Depression, region of scenic value and high ecotourism potential. Based on researches performed specifically for the Salto City, this article aims to analyze the city considering the criteria of Green and Blue seals of the State Secretariat of Environment and LAB Verde Seal, of the University of São Paulo. Furthermore, it is intended to propose adjustments to highlight and enhance the Roteiro dos Bandeirantes at that region, integrating it to the city and aiming to make it more resilient and sustainable.
\end{abstract}

Keywords: Green Infrastructure, Community Vegetable Gardens, Roteiro dos Bandeirantes, Sustainability and Resilient City

\section{O ROTEIRO DOS BANDEIRANTES E A CIDADE DE SALTO}

O Roteiro ${ }^{2}$ dos Bandeirantes é resultado de um Projeto Federal chamado de Programa de Regionalização do Turismo ${ }^{3}$ - Roteiros do Brasil que surgiu do aprofundamento do Plano Nacional do Turismo: diretrizes, metas e programas 2003 - 2007. Segundo Baldi (2012) o Roteiro foi instituído em 2003, pela Resolução Estadual nº 16.

\footnotetext{
${ }^{1}$ Bandeirantes were the members of colonial exploratory expeditions.

2 Segundo o Ministério do Turismo o roteiro turístico é um itinerário caracterizado por um ou mais elementos que lhe conferem identidade, definido e estruturado para fins de planejamento, gestão, promoção e comercialização turística das localidades que formam o roteiro.

${ }^{3}$ O Programa de Regionalização do Turismo propõe a estruturação, o ordenamento e a diversificação da oferta turística no país e se constitui no referencial da base territorial do Plano Nacional de Turismo.
} 
Segundo (GAVIOLLI, 2008, p. 410) "O roteiro é baseado no agrupamento dos atrativos ligados à temática bandeirista, somado às facilidades e acessos aos municípios integrantes, originando um produto diferenciado e com maior valor agregado.".

O roteiro tem cerca de 180 quilômetros que passam por oito cidades: Santana do Parnaíba, Araçariguama, Pirapora do Bom Jesus, Cabreúva, Itu, Salto, Porto Feliz e Tietê, e pode ser visitado no período de um ou dois dias, apresentando indicação de 72 locais para hospedagem segundo site oficial do roteiro.

O roteiro é muito conhecido por escolas de ensino fundamental e médio para caracterizar estudos do meio e práticas de disciplinas como história, geografia, ciências, biologia, química e educação ambiental. Outro público frequente no roteiro são os ciclistas, onde, em consulta a sites especializados de ciclismo, pode-se encontrar vários mapas com rotas de ciclo turismo na região.

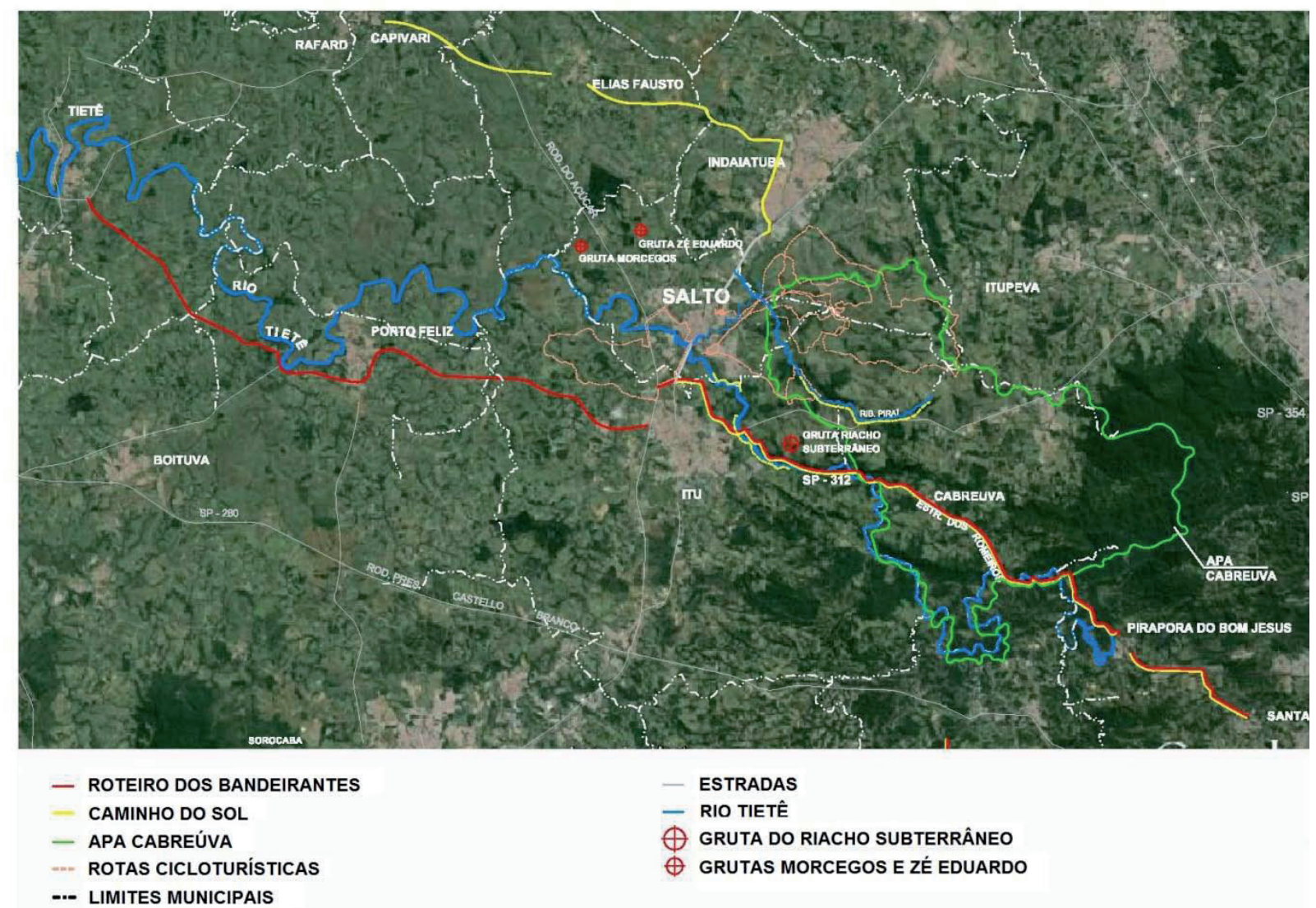

Figura 1: A REGIÃO DE SALTO. Fonte Google Earth. Data da Imagem 4/9/2013 23014'22.42"S $47^{\circ} 20^{\prime} 11.91$ "O elev $551 \mathrm{~m}$ altitude do ponto de visão 94,36Km. Adaptado: Sandra Schaaf Benfica Out.2013 
A cidade de Salto, ponto central da pesquisa deste artigo, além de fazer parte do Roteiro dos Bandeirantes também está incluída no roteiro turístico Caminho do Sol, com cerca de 240 quilômetros. O Roteiro do Caminho do Sol é considerado um roteiro preparativo para o caminho de Santiago de Compostela na Espanha e, portanto, recebe também um público de romeiros. O Roteiro dos Bandeirantes apresenta como elo, além da temática bandeirista, o Rio Tietê, o único que corta o Estado de São Paulo rumo ao Rio Paraná e que no caminho dos Bandeirantes serviu de estrada e alimentação, sendo o responsável pela criação de vários povoados na época das bandeiras e que posteriormente se transformaram em cidades que auxiliaram no desenvolvimento do interior do Estado de São Paulo.

O relevo da região compreende a transição entre o Planalto Atlântico e a Depressão Periférica ${ }^{4}$. Segundo (CARPI JUNIOR, 2010), o

"Planalto Atlântico Florestado consiste na área mais elevada do Estado de São Paulo, geralmente acima de 700 m, com planaltos, serras, morros, vales encaixados e declividade mais acentuada, ocupada originariamente por matas. Assenta-se sobre rochas do Complexo Cristalino, que dispondo-se no terreno geralmente com grandes variações verticais e horizontais, traduzemse em grandes variações espaciais no relevo e tipos de solos da região".

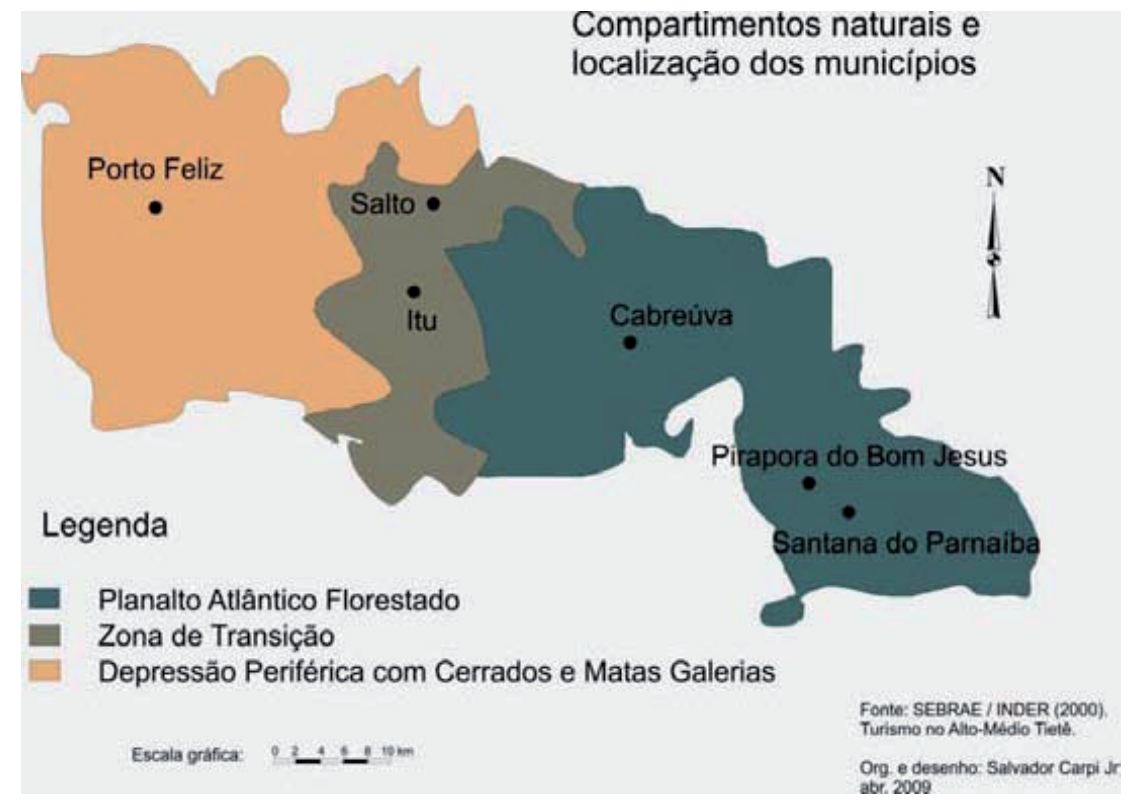

\section{Figura 2:}

Compartimentos Naturais E Localização Dos Municípios. Fonte: Sebrae/Inder (2000) Turismo no Alto-Médio Tietê. Org. e desenho: Salvador Carpi Jr Abr. 2009

\footnotetext{
${ }^{4}$ CARPI JUNIOR usa as denominações "Planalto Atlântico Florestado" e "Depressão Periférica recoberta com relictos de cerrado e mata atlântica" bers of colonial exploratory expeditions.
} 
Nesta região, também encontra-se a Serra do Japi e Guaxinduva, de cobertura vegetal original de Mata Atlântica, e que fazem parte da APA Cabreúva. A APA Cabreúva inclui também parte dos municípios de Itu, Salto e Indaiatuba, com a finalidade de proteger as nascentes de importantes cursos d'água. Ao sul, destaca-se a Mata Atlântica, sobre as Serras do Japi e Guaxatuba, os vales do Tietê e os mananciais que abastecem Cabreúva e, em direção ao norte, o relevo vai se atenuando, com ocorrência de matacões, até a várzea do Rio Piraí. Essa região tem um grande valor cênico, e o patrimônio natural, paisagístico, histórico, religioso e cultural tem poder de estimular o turismo ecológico. A Serra do Itaguá divide as águas dos Rios Tietê e Piraí, apresentando valor de patrimônio natural devido à ocorrência de matacões de granito. Segundo (MONDENESI,1974 apud CARPI JUNIOR, 2010), os Rios Tietê e Piraí apresentam influências de falhas geológicas, com vertentes abruptas, canyons, corredeiras e quedas.

Ainda segundo (CARPI JUNIOR, 2010), a Depressão Periférica

"corresponde a uma área do Estado de São Paulo relativamente rebaixada em relação aos arredores, com altitudes geralmente entre 500 e 700 m, onde predomina o relevo de colinas amplas e suaves, com pequena declividade, ocupada inicialmente por matas ciliares, cerrados e campos.(...) Assim, deslocando-se do Planalto Atlântico para o interior, o contato com a Depressão Periférica representa o início de horizontes mais dilatados e o fim dos relevos mais íngremes do Planalto Atlântico, bem como os grandes rios que banham estas cidades tem, neste contato, o início de seus maiores trechos navegáveis. A transição entre Planalto Atlântico e a Depressão Periférica é caracterizada também pela existência de uma "fall line", ou linha de quedas, que compreende algumas cachoeiras, corredeiras e pequenas quedas, como a cachoeira do rio Tietê (Salto de Itu-Guaçu), em Salto e a cachoeira de Itupararanga, em Votorantim. A presença dessa linha de quedas foi a responsável pelo início da industrialização em Sorocaba, Itu e Salto no início do séc. XX, pois permitiu o aproveitamento da energia elétrica para o funcionamento das primeiras fábricas, algumas em funcionamento até os dias atuais."

De acordo com esse olhar geográfico (CARPI JUNIOR, 2010), são considerados como elementos fundamentais do patrimônio natural do Vale do Médio Tietê: a zona de contato entre o Planalto Atlântico e a Depressão Periférica, o rio Tietê, os canyons dos rios Tietê e do rio Piraí, os matacões de granito as áreas de mata nativa e os vestígios de caatinga. 
O Canyon do Tietê tem um valor fundamental como patrimônio natural e uma beleza cênica de valor, com suas quedas, afloramentos rochosos, matacões e mirantes. Abriga condições ecológicas para a manutenção da biodiversidade local, juntamente com a grande quantidade de nascentes e cursos d'água encachoeirados da região, apresentando grande diversidade de vegetação e fauna, tanto na Mata Atlântica quanto na mata ciliar.

O turismo histórico-cultural, turismo religioso e ecoturismo estão presentes neste roteiro, com diversas atrações para visitação além de calendário com atividades festivas.

No entanto, o roteiro apresenta diversos problemas como pouca divulgação e sinalização, falta de investimentos financeiros e infraestrutura turística por parte tanto das Prefeituras quanto do Governo Estadual. Segundo (GAVIOLLI, 2008) há falta de coesão entre os atrativos turísticos das cidades do roteiro focados na temática bandeirista, isso ocorre em função da ausência de uma pesquisa mais profunda que identificasse como se deu a atividade bandeirista no espaço geográfico de cada cidade e quais foram as influências herdadas dos bandeirantes tanto de cunho histórico como arquitetônico.

\section{METOLOGIA}

Para o desenvolvimento da pesquisa, inicialmente foi realizada uma entrevista com o Secretário Municipal do Meio Ambiente de Salto Sr. Eng. João De Conti Neto, buscando compreender de que forma o município "atua" frente a sustentabilidade e a pontuação do Município na Certificação Ambiental do Estado de São Paulo - o Selo Verde / Azul.

Outras informações coletadas na entrevista foram os questionamentos referentes aos critérios da certificação do LABVERDE, que resultaram numa leitura e pontuação do grupo de pesquisa para a análise ambiental.

Para entender a importância do roteiro turístico no contexto da cidade, buscou-se informações em sites sobre turismo, geografia e patrimônios naturais, roteiro ciclísticos e referências hoteleiras que atendessem ao roteiro em estudo.

Outro método utilizado foi a pesquisa bibliográfica, que auxiliou no aprofundamento conceitual e referências de casos sobre cidades sustentáveis e infraestrutura verde. 
Os dados coletados foram mapeados em bases cartográficas do IBGE na escala 1:50.000 e cruzados com imagens satélites adquiridas através do Google Earth.

\section{A CIDADE DE SALTO}

A cidade de Salto pertence à região administrativa de Sorocaba. Apresenta cerca de 108 mil habitantes, em uma área de $133 \mathrm{~km}^{2}$, densidade demográfica de 814 habitantes $/ \mathrm{km}^{2}$ e um grau de urbanização de $99 \%$, tendo a maior participação do PIB da cidade vindo do setor de serviços - cerca de 64\% (SEADE - FUNDAÇÃO SISTEMA ESTADUAL DE ANÁLISE DE DADOS, 2013). O IDHM da cidade em 2010 foi 0,780, ficando em $128^{\circ}$ lugar (PNDU - PROGRAMA DAS NAÇÕES UNIDAS PARA O DESENVOLVIMENTO, 2013).

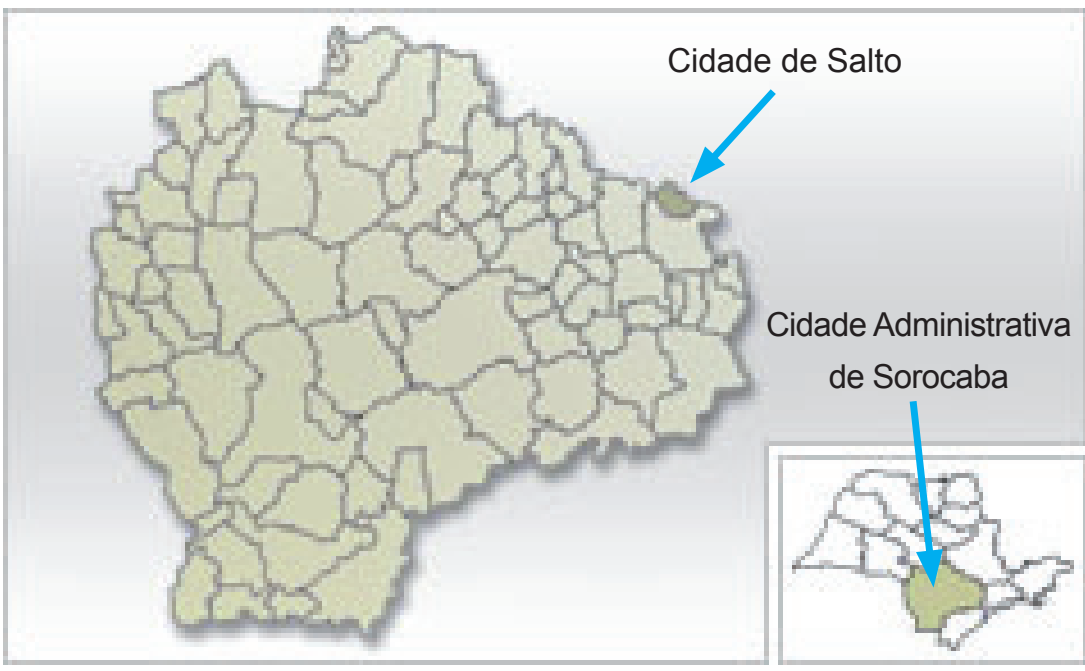

Figura 3: Mapa de localização da cidade de Salto. Fonte: Seade - Fundação Sistema Estadual de Análise de Dados (2013)

Conforme os dados apresentados, trata-se de uma cidade quase totalmente urbanizada, o que foi confirmado na visita realizada à cidade e na entrevista com o Sr. Eng. João De Conti Neto, Secretário Municipal do Meio Ambiente. O Secretário esclareceu as pontuações e informações contidas no protocolo do município no Programa ${ }^{5}$ Verde Azul da Secretaria do Meio Ambiente do Estado de São Paulo de 2012 e respondeu aos questionamentos do grupo de pesquisa referente aos critérios existentes na certificação do Selo LABVERDE6 .

\footnotetext{
${ }^{5}$ Trata-se de um programa ambiental da Secretaria de Estado do Meio Ambiente, cujo objetivo é ganhar eficiência na gestão ambiental através da descentralização e valorização da base da sociedade. O Programa visa estimular e capacitar as prefeituras a implementarem e desenvolverem uma Agenda ambiental estratégica (2013).

${ }^{6}$ Refere-se a um experimento - SELO LABVERDE destinado à avaliação e certificação ambiental de empreendimentos e projetos com ênfase em Localização Sustentável, criado em 2008 pelo laboratório da FAUUSP sob coordenação da Prof. ${ }^{a}$ Dra. Maria de Assunção Ribeiro Franco.
} 
Dentre os problemas identificados pelo protocolo do Programa Verde Azul, podemos citar:

- Resíduo da construção civil: Ausência de um plano de reaproveitamento;

- Mata ciliar: falta de definição de metas para as áreas a serem recuperadas, ações de recuperação ou manutenção destas matas, tão pouco a existência de um cronograma para esta recuperação;

- Arborização urbana: não há plano de arborização nem algum projeto piloto de recuperação da floresta urbana;

- Uso da água: não há identificação dos grandes usuários deste recurso;

- Estrutura Ambiental: na época do preenchimento do protocolo não havia estrutura administrativa, responsável legal ou conselho ambiental na cidade, no entanto, estes itens passaram a existir com a mudança da prefeitura e hoje a cidade tem uma secretaria do meio ambiente - porém ainda com estruturas física, material e financeira muito restrita;

Já a avaliação da certificação LABVERDE é mais ampla e feita em quatro escalas: regional, urbana, setorial e local. Dentre os problemas identificados na avaliação da escala regional, pode-se constatar:

- A gestão das bacias em associação com os municípios vizinhos é feita de forma muito tímida, apenas com um evento chamado de Jornada do Rio Tietê. Na cidade de Salto o Rio Tietê apresenta-se com poluição, tendo como consequência a formação de uma leve espuma e odores desagradáveis. Esta poluição está presente ao longo do curso do rio desde a cidade de São Paulo;

- Não há estudos da captação das águas subterrâneas;

- Não há estudos de recuperação da mata nativa;

- Não há registro de produção de outra fonte de energia que não seja a hidroelétrica;

- Apresenta uma área rural muito pequena não havendo produção de alimentos "in loco";

- Não há controle de expansão urbana, sendo inclusive incentivada a criação de novos loteamentos previstos no plano diretor que está em vigor;

- Tendência da cidade a se tornar "cidade dormitório", com estrutura de trabalho e lazer que não atendem as necessidades da população local; 
Dentre os problemas identificados na avaliação da escala urbana, pode-se constatar:

- Existência de ciclovia "fantasma" desenvolvida em local com muito morro, portanto não sendo utilizada pela população;

- Ocupação indevida das APP's, o que certamente causa problemas ambientais de alto valor.

$\mathrm{Na}$ escala setorial os principais problemas encontrados foram:

- Não há um desenvolvimento compacto da cidade, apresentando um crescimento desordenado, sem planejamento;

- Não há diversidade de uso na cidade, havendo predominância de construções residenciais e comércio;

- Não foi observada a existência de ruas exclusivas para pedestres;

- Não há registros de exigência de adaptação para acessibilidade universal em construções antigas, apenas para novas construções. As ruas são muito estreitas não sendo eficientes quanto à fluidez do trânsito, são áridas - sem vegetação adequada, o que contribui para a formação de ilhas de calor e não apresentando ciclovias;

Na escala local, percebeu-se os seguintes problemas:

- Não há construções sustentáveis na cidade;

- Não há reuso de águas pluviais nem de águas servidas;

- Não há muita preocupação de reuso e adaptação de edifícios antigos para novos usos;

- Não há preocupação de recuperar as áreas de solos degradados;

- Não há ação efetiva de redução de ilhas de calor;

- Trata-se de um município com alto índice de incidência solar - 5,25 KWh/m dia - segundo a Secretaria de Energia do Estado de São Paulo (2013). As temperaturas são baixas no mês de julho (média de 10,7 graus) e altas em 
fevereiro - cerca de 30 graus. A incidência de chuva é muito semelhante das cidades ao redor como Sorocaba e Itu, apresentando períodos de pouca chuva entre julho e agosto ( $34 \mathrm{~mm}$ ) e períodos de mais chuva entre janeiro e fevereiro (208 mm), (CEPAGRI - CENTRO DE PESQUISAS METEREOLÓGICAE CLIMÁTICA APLICADAS À AGRICULTURA, 2013)

Por outro lado, a cidade apresenta três parques: o Parque de Lavras, o Rocha Moutonnée e o Parque do Lago, com possibilidade de criação de um quarto, o parque dos Matacões entre a cidade de Salto e Itu, região em que localiza-se a maior caverna de granito da América do Sul e a sexta maior do mundo (OLIVEIRA; FERRÃO, 2012), a Gruta do Riacho Subterrâneo.
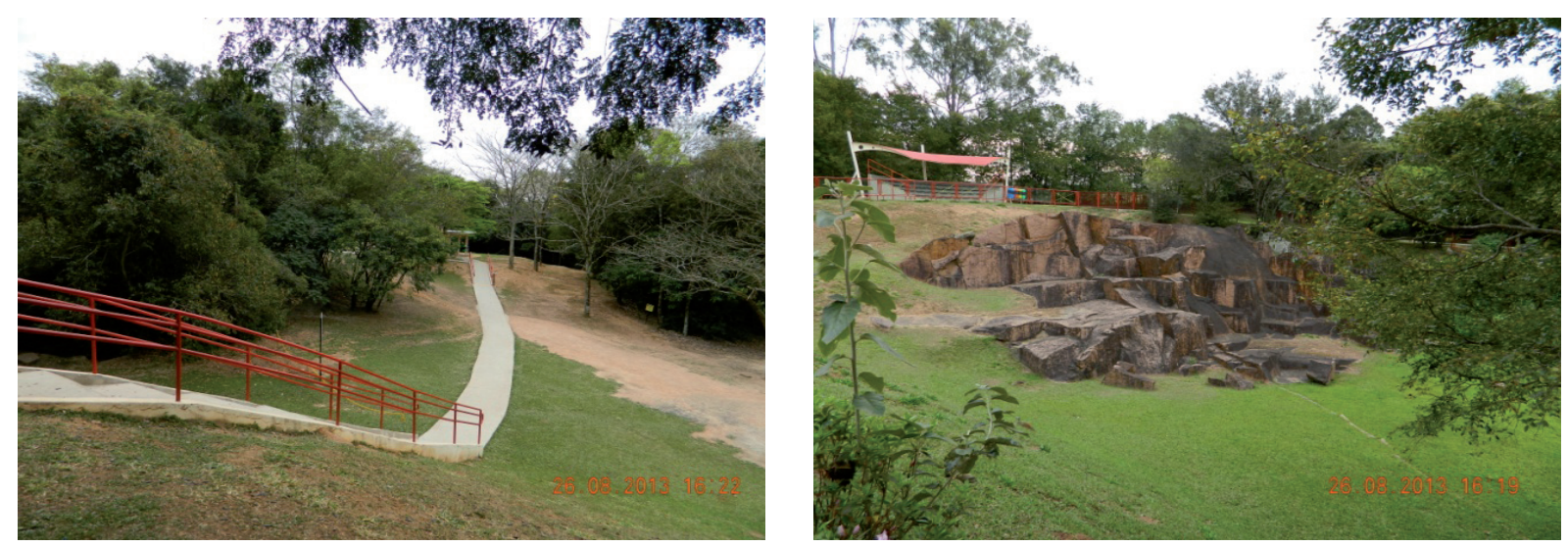

Figuras 4 e 5: Parque Rocha Moutonnée. Fonte: acervo pessoal de Tatiana R. S. Simão, Ago 2013

O Parque Rocha Moutonnée tem uma área de $43.338 \mathrm{~m}^{2}$ e apresenta um valor geológico muito grande, pois neste sitio geológico há comprovações do fenômeno de glaciação na era paleozóica que ocorreu a cerca de 270 milhões de anos. Além disso, trata-se de um patrimônio histórico e cultural tombado em 1990 pelo CONDEPHAAT ${ }^{7}$ (WENDLER; MERLIN, 2010).

O Parque de Lavras está localizado onde antigamente ficava a antiga usina hidroelétrica que tinha o mesmo nome do parque. Com uma área de aproximadamente 140 mil $\mathrm{m}^{2}$ este parque além de incorporar em seu espaço a imagem da santa padroeira e um museu, propicia também uma boa leitura da memória história e paisagística da cidade (OLIVEIRA; FERRÃO, 2012).

\footnotetext{
${ }^{7}$ Conselho de Defesa do Patrimônio Histórico, Arqueológico e Artístico do Estado de São Paulo.
} 

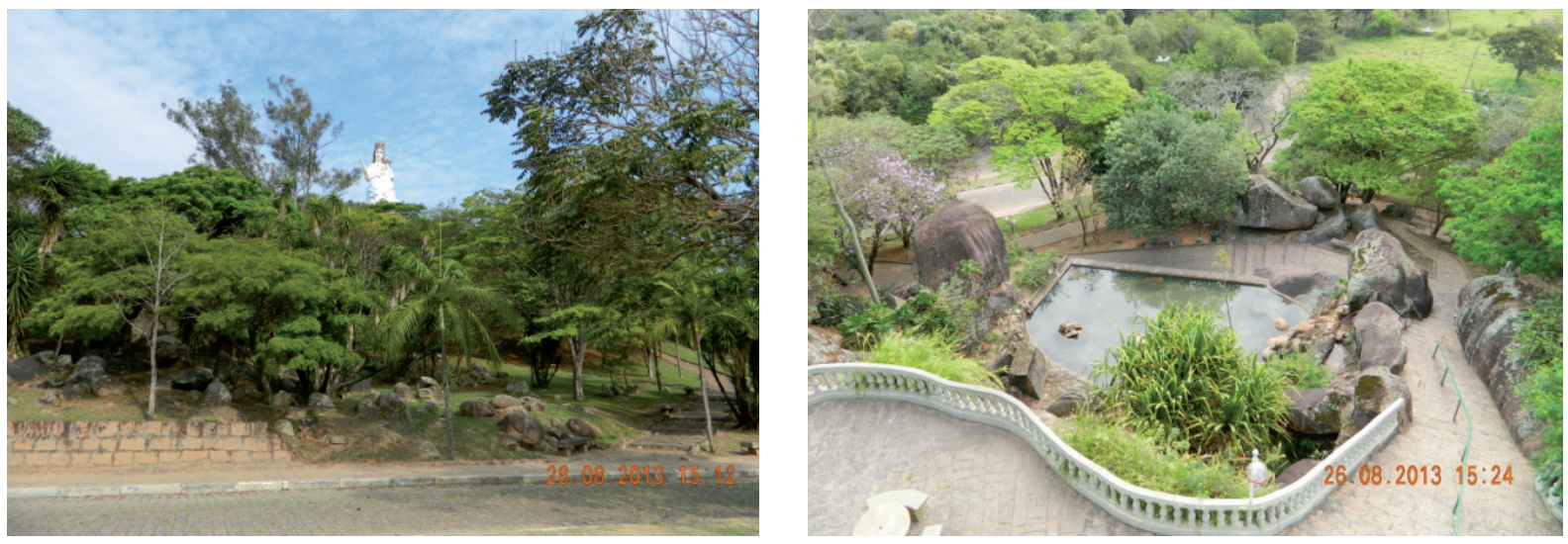

Figuras 6 e 7: Parque de Lavras. Fonte: acervo pessoal de Tatiana R. S. Simão, Ago 2013.

O Parque do Lago, por sua vez, trata-se de um parque de lazer, com cerca de 214 mil $\mathrm{m}^{2}$, que, além de equipamento, pistas de caminhada, ciclovia, quadras poliesportivas, áreas de aeromodelismo e playground, também trabalha com questões de educação ambiental (OLIVEIRA; FERRÃO, 2012).
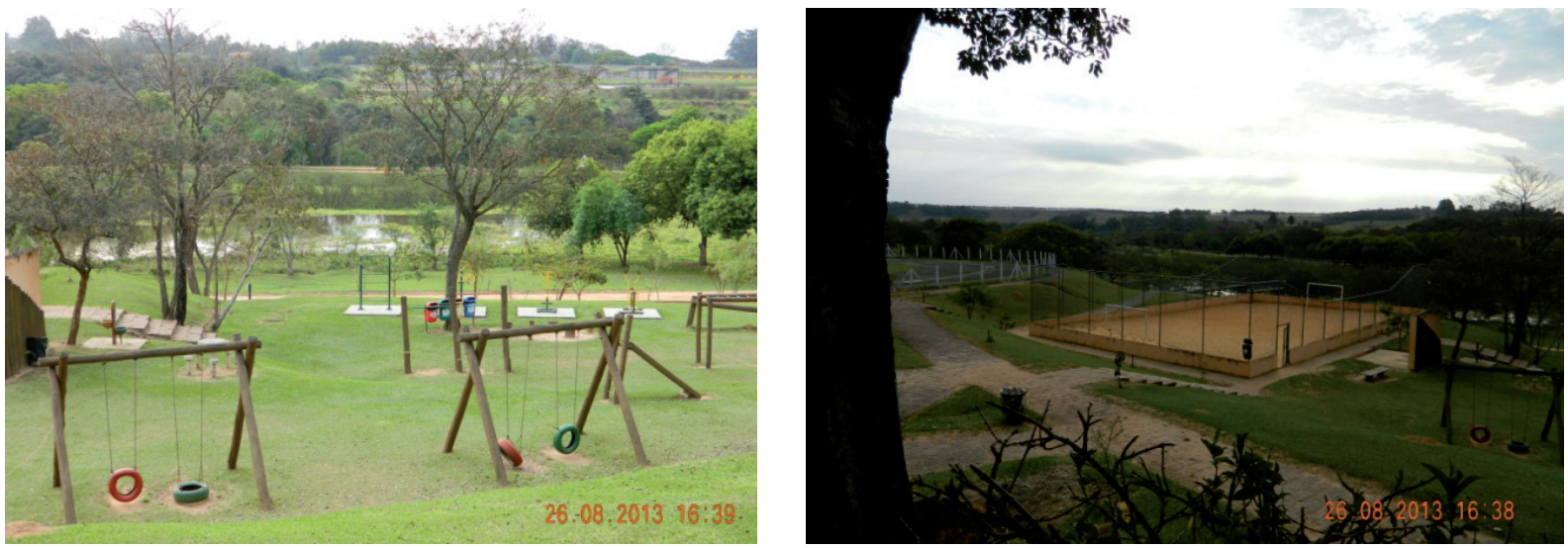

Figuras 8 e 9: Parque do Lago. Fonte: acervo pessoal de Tatiana R. S. Simão, Ago 2013.

Os três parques da cidade apresentam-se em regiões distintas e sem qualquer conexão paisagística e elementos arquitetônicos que os interligue visando melhorar a infraestrutura verde do centro da cidade em questão.

O elevado potencial turístico, histórico e religioso natural tem sido pouco aproveitado, não levando em conta as fazendas históricas e a própria história do Rio Tietê - como a cachoeira Itu-Guaçu em Salto e a Usina Hidrelétrica São Pedro, construída em 1911, em ITU, a Igreja Matriz, além de estar ameaçado pela expansão desordenada de loteamentos e condomínios. Segundo Suguimoto (2007), as pessoas da cidade primeiro se lem- 
bram do rio Tietê pelo seu odor, depois pela sua bela cachoeira. Alguns prefeririam até que o Rio não existisse, pois não acreditam que a poluição do rio possa ter uma solução.
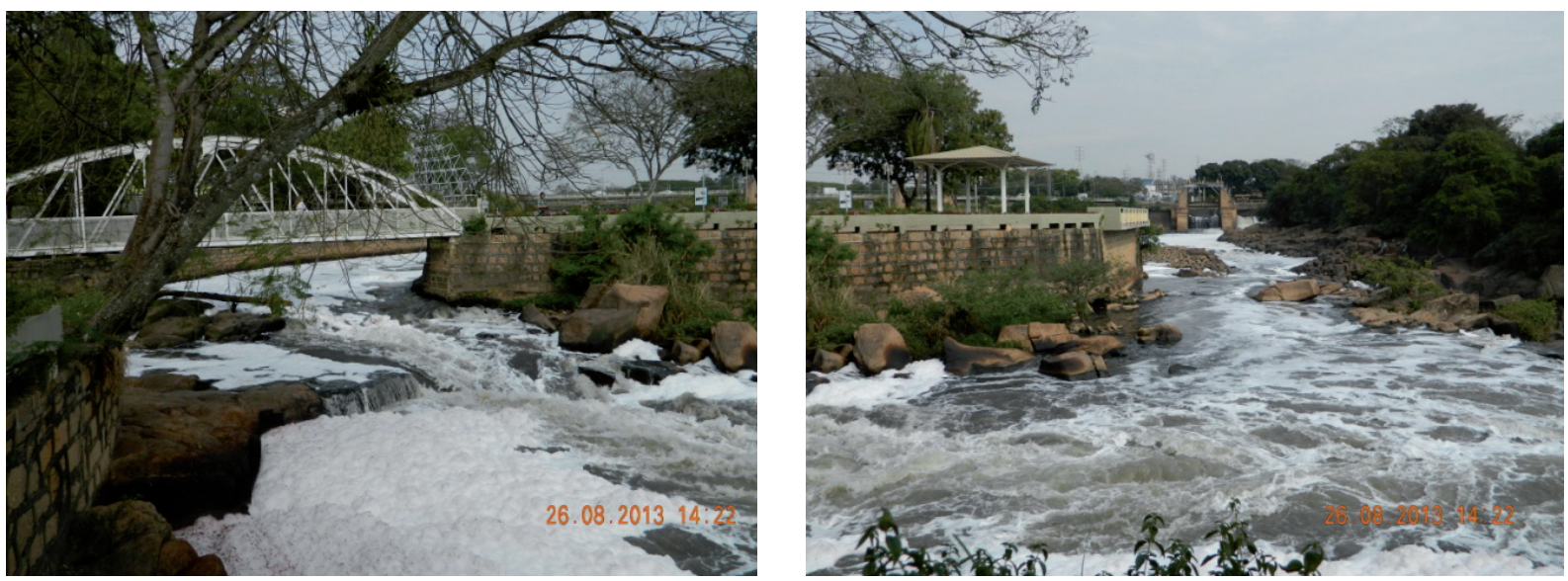

Figuras 10 e 11: Complexo da Cachoeira. Fonte: acervo pessoal de Tatiana R. S. Simão, Ago 2013
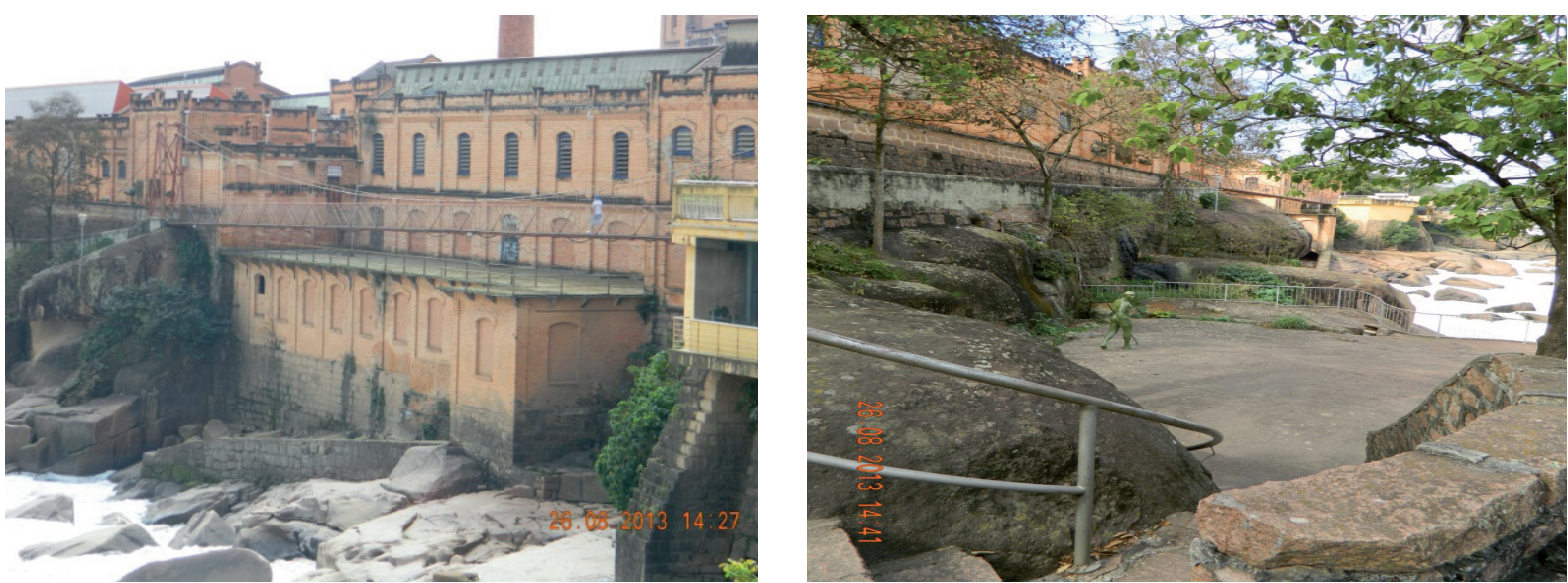

Figuras 12 e 13: Antiga fábrica Brasital com a ponte Pensil e o Jardim de Esculturas. Fonte: acervo pessoal de Tatiana R. S. Simão, Ago 2013
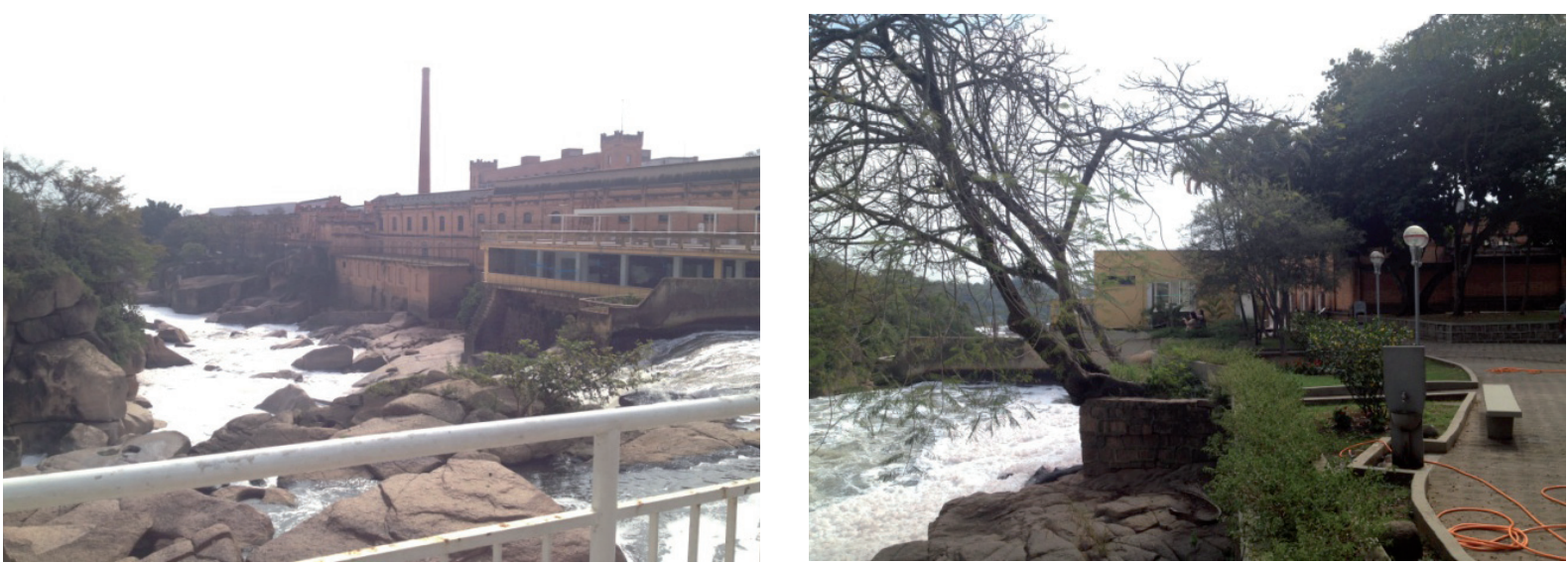

Figuras 14 e 15: Memorial do Rio Tietê que fica no Complexo Turístico da Cachoeira. Fonte: acervo pessoal de Sandra Schaaf Benfica , Ago 2013 


\section{INFRAESTRUTURA VERDE}

Em (HERZOG; ROSA, 2010, p. 10) "A infraestrutura verde consiste em redes multifuncionais de fragmentos permeáveis e vegetados, preferencialmente arborizados (inclui ruas e propriedades públicas e privadas), interconectados que reestruturam o mosaico da paisagem."

Para CORMIER e PELLEGRINO (2008) a infraestrutura verde pode ser vista como uma rede de espaços interconectados, composta por áreas naturais e outros tipos de espaços abertos que conservam os valores dos ecossistemas naturais e suas funções, que seja de mananciais, lazer, controle ambiental e trazendo benefícios para a sociedade. Ela pode ser vista como uma tapeçaria formada por espaços abertos dentro de uma cidade ou ao seu redor.

A infraestrutura verde pode ser composta por vários elementos, como parques, praças, corredores verdes, manejo de enchentes, jardins de chuva, canteiros pluviais, biovaletas, lagoa pluvial, teto verde, grade verde, hortas urbanas. No entanto, para (FRANCO, 2010), estes elementos devem conservar os valores e funções ecológicas, sustentar o ar e água limpos e manter a ampla variedade de benefícios para as pessoas e a vida selvagem, que nortearão as ações do planejamento e desenvolvimento territorial.

Para FRANCO, 2010, a infraestrutura verde pode trazer vários benefícios:

1. Melhora a qualidade do ar promovendo a saúde humana;

2. Sequestro de carbono da atmosfera;

3. Amortiza entre temperaturas altas e baixas no microclima urbano;

4. Protege, conserva e recupera a biodiversidade na área urbana;

5. Auxilia na contenção de erosão;

6. Promove atividades contemplativas, esportivas e de lazer;

7. Promove a paisagem urbana;

8. Melhora a permeabilidade do solo, reduzindo as enchentes;

9. Articula e interliga os espaços verdes;

10. Promove a seguridade urbana;

11. Protege áreas de fragilidade ecológica;

12. Promove a imagem e a identidade de lugares urbanos.

No entanto, para que seja eficiente a infraestrutura verde, FRANCO, 2010 entende que as ligações entre os corredores verdes, que interligam os diversos pontos, devam ser feitos com transporte não motorizado e não poluente, como andar a pé, transporte 
ciclo-viário, infraestrutura viária e de metrô eficientes. Além disso, é importante também haver uma conexão com espaços culturais, de esporte e lazer.

FRANCO, 2013 aponta as cidades de Moscou, Lagos na Nigéria, Santiago do Chile e Addis Abeba na Etiópia como cidades mais verdes, com informações contidas nas apresentações do $\mathrm{C}^{4} 0^{\circ}$. Estas cidades apresentavam grandes problemas com quantidade de dióxido de carbono lançados na atmosfera, ondas de calor, poluição ambiental, alterações climática, aridez e aumento de temperaturas e implantaram políticas públicas como plantio compensatório de vegetação, preservação e desenvolvimento de áreas verdes, alterações em Plano Diretor transformando áreas de terra em áreas verdes, entre outras ações que conduziram estas cidades a melhorar os aspectos da qualidade do ar e serem consideradas cidades mais verdes.

\section{PROPOSTA DE INFRAESTRUTURA VERDE PARA A CIDADE DE SALTO}

Após compreender um pouco da importância do Roteiro dos Bandeirantes, da cidade de Salto com seus problemas e o conceito sobre infraestrutura verde, este artigo propõe-se a apresentar diretrizes que visam solucionar parte dos problemas existentes nesta cidade.

Dentre os problemas apresentados, focou-se em alguns que são: falta de um plano de arborização para a cidade, inexistência de uma ciclovia e rua de pedestres, não há diversidade de uso da cidade, a cidade não tem ações para a redução das ilhas de calor e a falta de produção de alimentos locais.

A cidade apresenta potencial turístico efetivo, principalmente pela existência dos seus três parques (Parque de Lavras, o Rocha Moutonnée e o Parque do Lago), com projeto de criação de mais um na divisa com Itu (Parque dos Matacões), mas que apresentam-se desconexos e sem qualquer elemento que os valorize como parte da cidade ou que auxilie na solução de alguns problemas de Salto.

Portanto, as diretrizes resultantes deste trabalho de pesquisa vão de encontro com a proposição da criação de uma infraestrutura verde que interligue os parques e passe também pelos pontos turísticos que remetem a memória histórico/cultural do Roteiro dos Bandeirantes, como o Museu da Cidade e o Caminho das Esculturas, conforme pode ser visto na figura 16.

\footnotetext{
${ }^{8}$ O C40 ( Climate Leadership Group) foi criado em outubro de 2005 por Ken Livingstone, na época prefeito de Londres, que tem dois objetivos principais: criar cooperação na redução da emissão de gases do efeito estufa e promover ações em grupo entre empresas, administrações públicas e a sociedade, visando combater as mudanças climáticas (C40 SÃO PAULO SUMMIT, 2013).
} 


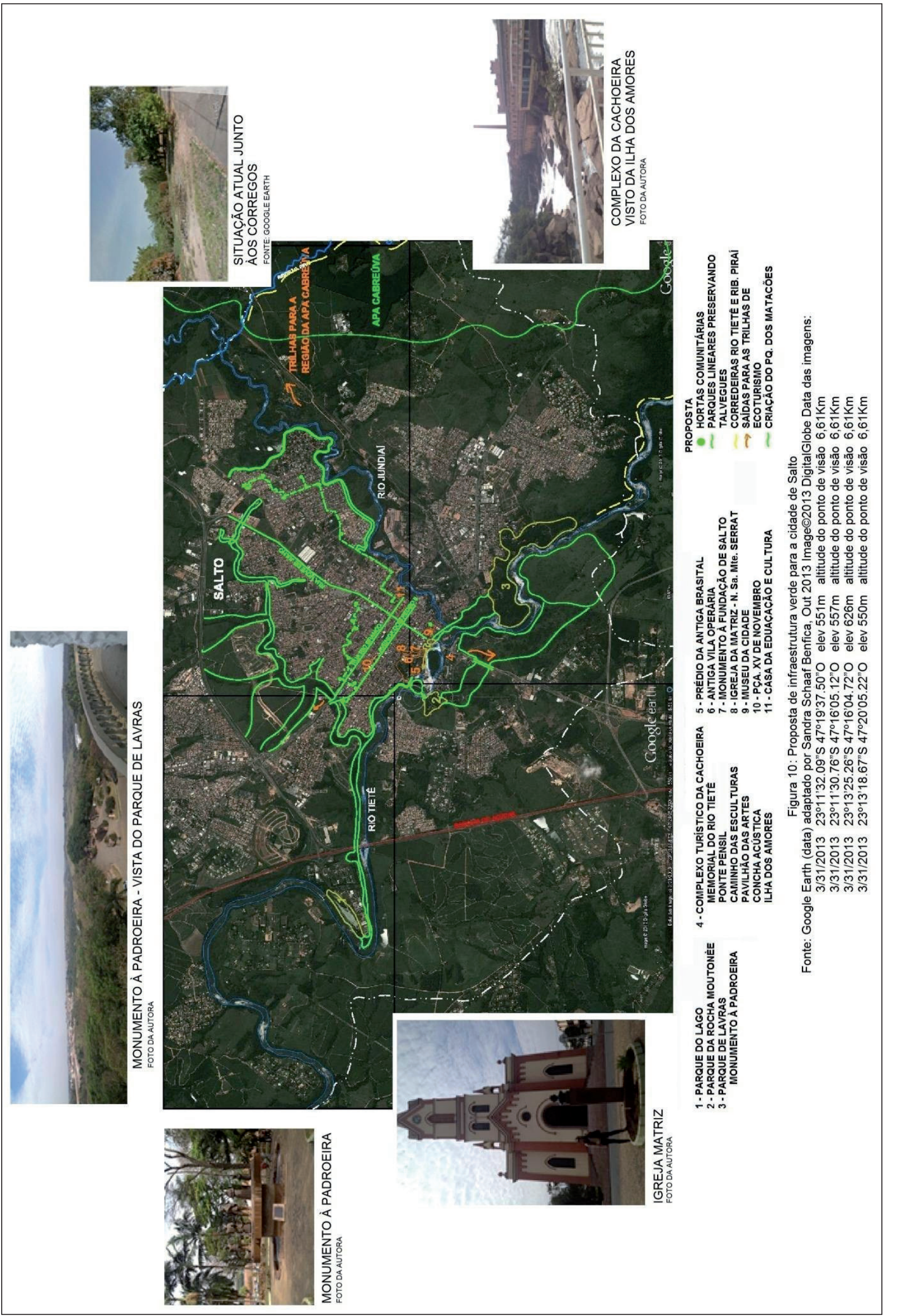

$\frac{0}{\frac{\pi}{5}}$ 
Os pontos turísticos se localizam muito próximos ao Rio Tietê, com exceção da Praça XV de Novembro, a Casa de Educação e Cultura e a Igreja Matriz.

- Os parques também permeiam o Rio Tietê, porém sem nenhuma ligação. A proposta para os parques é integrá-los através de um parque linear, formando um cordão verde ao redor da cidade à medida que se junta às Áreas de Proteção Permanente do Córrego do Ajudante (na figura 16, à esquerda) e seus afluentes e também ao cordão que se formaria próximo ao Rio Jundiaí (na figura 16, à direita) para a criação de hortas comunitárias.

- Tanto o cordão do Córrego do Ajudante e seus afluentes como o cordão do Rio Jundiaí formariam também parques lineares que, além de proteger os talvegues e os rios Tietê e Jundiaí da ocupação indevida de suas margens, poderiam abrigar um projeto de hortas comunitárias com o fim de contribuir para a autossuficiência do município na questão da produção de hortifruticulturas, hoje quase inexistente no município.

- Ainda estudando o fator da produção de hortifruticulturas, e, levando-se em consideração a alta taxa de ocupação da cidade, os terrenos ainda vazios, localizados em pontos estratégicos da cidade, serviriam também de hortas comunitárias para atender aos moradores e comerciantes dos bairros centrais, formando uma "rota verde".

- Como exemplo para outras ruas, os eixos mais movimentados da cidade - Rua Rio Branco, Avenida Dom Pedro II e Rua Nove de Julho, que apresentam maior trânsito e não possuem infraestrutura verde para os pedestres, receberiam melhorias como rearborização, acessibilidade, jardins de chuva, biovaletas formando, junto com os parques lineares dos talvegues e dos rios Tietê e Jundiaí anteriormente citados, verdadeiros corredores verdes.
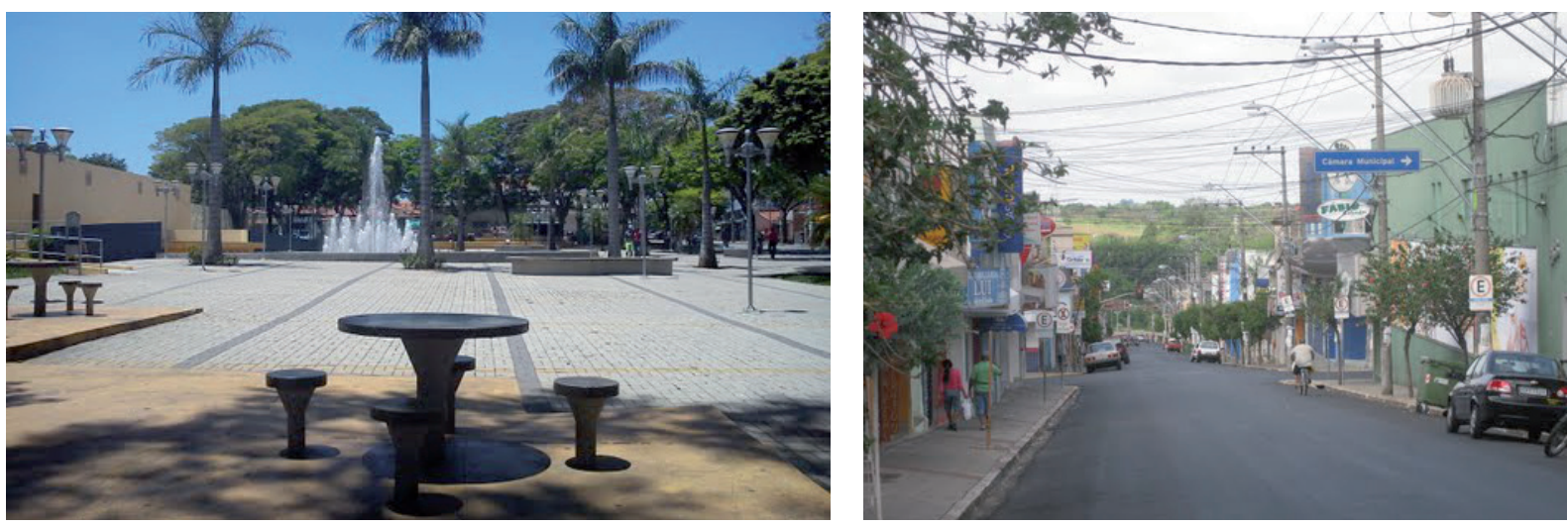

Figura 17: Praça XV de Novembro. Fonte: Google Earth. Figura 18: Rua 9 de julho. Fonte: Google Earth. 


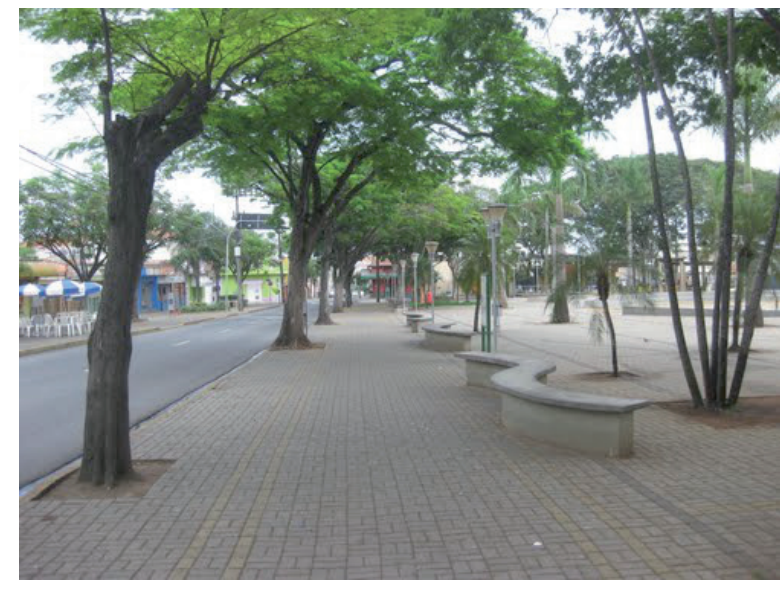

Figura 19: Avenida D. Pedro - Pça XV de Novembro. Fonte: Google Earth.

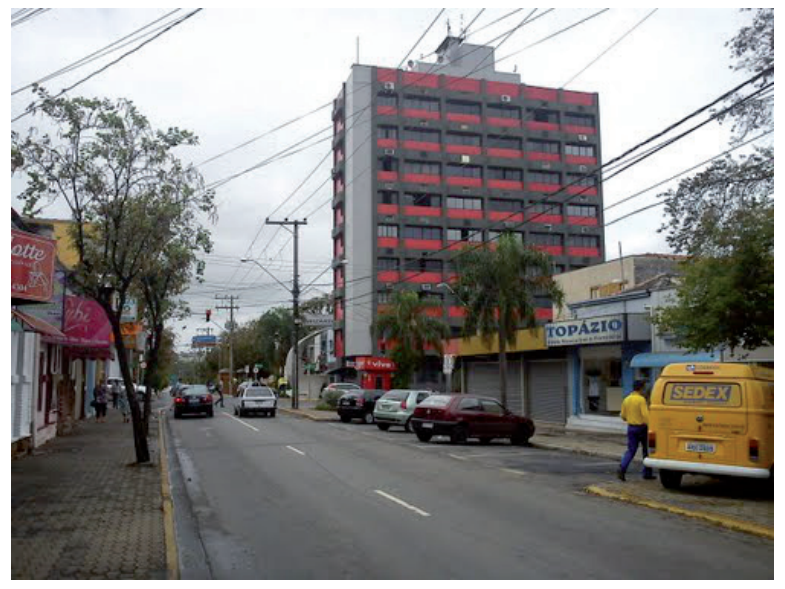

Figura 20: Av. D. Pedro. Fonte: Google Earth.

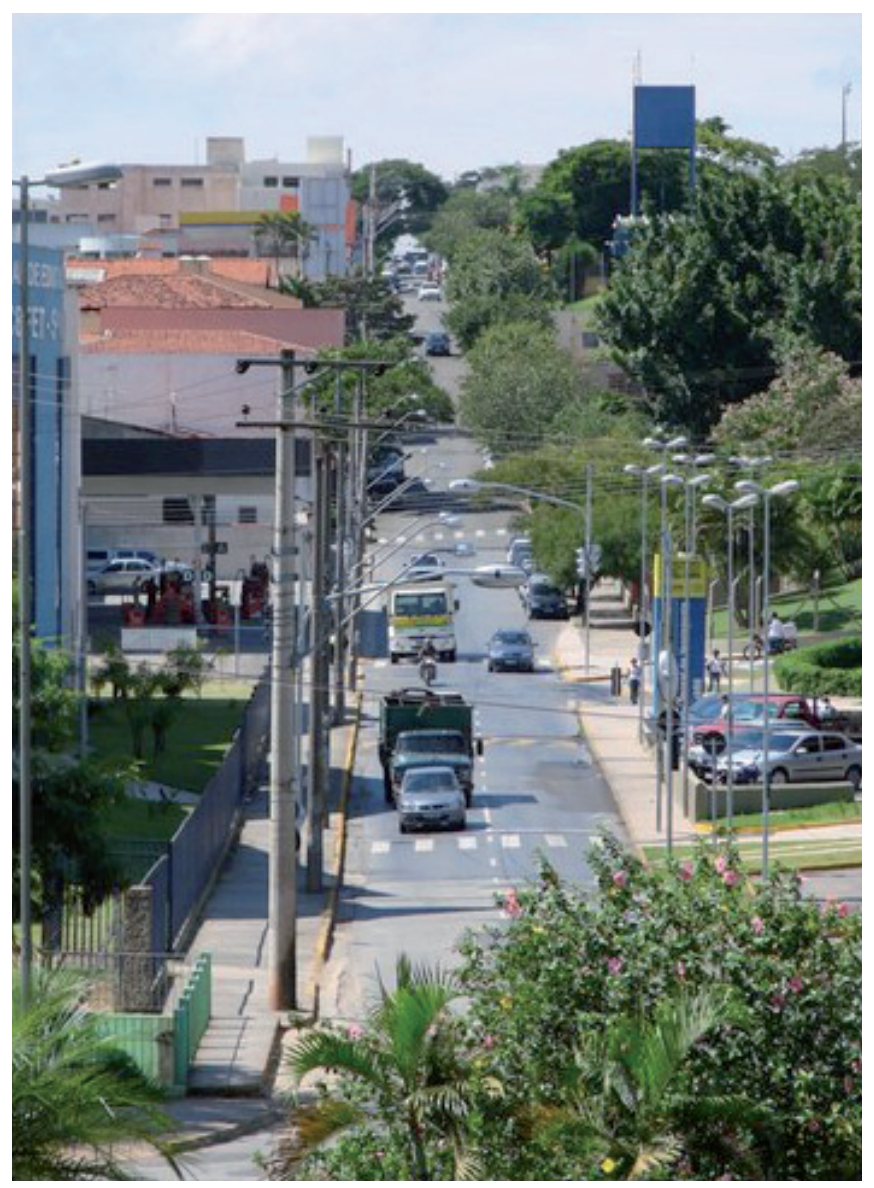

Figura 21: Rio Branco. Autor: Fábio Barros.

Fonte: Google Earth.

- Visando aproveitar os resíduos orgânicos que são coletados separadamente pela companhia de lixo que presta serviço para a cidade, estas hortas comunitárias seriam adubadas com adubos orgânicos vindo da compostagem destes resíduos. 


\section{CONCLUSÃO}

Após a pesquisa e a visita realizada, pode-se constatar que a cidade de Salto apresenta grande potencial turístico por diversos fatores, quer seja pelo ecoturismo, pelo ciclo turismo ou até mesmo pelo turismo religioso. No entanto, a cidade e os sites com informações turísticas da região não valorizam efetivamente o foco do Roteiro dos Bandeirantes e os fatos históricos que referenciam a temática do roteiro, mas sim os parques existentes na cidade. As poucas referências apresentadas ao Roteiro dos Bandeirantes surgem de forma simplista em um cartaz e esculturas em bronze no Complexo Turístico da Cachoeira.

Portanto, a criação de uma infraestrutura verde que interligue os parques às referências históricas valorizaria a importância destes pontos no Roteiro dos Bandeirantes. No entanto, seria necessário identificar novas referências históricas e realizar pesquisas mais amplas por parte dos órgãos responsáveis do município como Secretaria do Turismo e da Cultura a fim de aumentar o acervo a ser visitado na cidade.

A criação do Parque Linear integraria o Parque do Lago - situado a $5 \mathrm{~km}$ do centro - à cidade, porém, para isso, seria necessária a criação de uma estrutura verde sobre a Rodovia do Açúcar, que hoje o separa da cidade.

Situação semelhante ocorre com o Parque Rocha Moutonnée, que, apesar de ser muito próximo do centro, precisa uma ligação mais próxima com a cidade. A utilização do mesmo tipo de estrutura verde sobre o Rio Tietê criaria uma identidade visual para essas duas situações.

Através da figura 4 pode-se perceber a proposta de uma nova ligação entre os diversos bairros da cidade através criação da infraestrutura verde; a movimentação através dos parques e dos pontos de horta despertaria um novo olhar para a cidade. Os pontos de horta comunitária sugerem a criação de uma ciclovia que os interligue e estimule o habitante à circulação ecológica. Essas estruturas propostas reduziriam as ilhas de calor nas ruas estudadas e melhorariam a busca pela autossuficiência de alimentos da cidade.

Todas essas propostas devem repetir-se nos outros bairros e ruas da cidade, assim como devem ser incluídas no planejamento da expansão da cidade, devendo também ser realizado um estudo amplo sobre a criação de ruas exclusivas para pedestres.

Portanto, entende-se que ainda é possível recuperar e valorizar a cidade nos aspectos turísticos e históricos, tornando-a um modelo para o Roteiro dos Bandeirantes e 
para o Caminho do Sol, valorizando-os inclusive, e, através da atitude de uma cidade resiliente, aumentar o tempo de permanência de turistas nos roteiros e melhorar o desenvolvimento turístico e econômico da cidade.

\section{REFERÊNCIAS}

BALDI, Cauê. O patrimônio na contemporaneidade: um estudo sobre a preservação da paisagem cultural de Santana de Parnaíba. In: Seminário internacional Urbicentros, 3., 2012, Salvador, Bahia:. p. 1 - 20.

BRASIL. Ministério do Turismo. Coordenação Geral de Regionalização. Programa de Regionalização do Turismo - Roteiros do Brasil: Módulo Operacional 7 Roteirização Turística/ Ministério do Turismo. Secretaria Nacional de Políticas de Turismo. Departamento de Estruturação, Articulação e Ordenamento Turístico. Coordenação Geral de Regionalização. - Brasília, 2007.51 p. : il.

C40 SÃO PAULO SUMMIT (Brasil). Sobre o C40. Disponível em: <http://www. c40saopaulosummit.com/site/conteudo/index.php?in_secao=26\&lang=1>.

Acesso em: 12 out. 2013.

CEPAGRI - CENTRO DE PESQUISAS METEREOLÓGICA E CLIMÁTICA APLICADAS À AGRICULTURA. Clima dos Municípios Paulistas. Disponível em: <http://www.cpa. unicamp.br/outras-informacoes/clima_muni_510.html>. Acesso em: 13 out. 2013.

CARPI JUNIOR, SALVADOR - UNIDADES GEOAMBIENTAIS E PATRIMÔNIO NATURAL NO VALE DO MÉDIO TIETÊ, SÃO PAULO, BRASIL. In: VI Seminário LatinoAmericano de Geografia Física - II Seminário Ibero-Americano de Geografia Física Universidade de Coimbra, Maio de 2010. Disponível em: <http://www.uc.pt/fluc/cegot/ VISLAGF/actas/tema5/salvador>. Acesso em: 02.out.2013.

CADASTRO Nacional de Cavernas: Regiões do Brasil. Salto. Disponível em: <http:// www.cavernas.org.br/cnc/CavernasBW/RegioesBrasil\#>. Acesso em: 03 out. 2013.

CADASTRO Nacional de Cavernas: Regiões do Brasil. Itu. Disponível em: <http:// www.cavernas.org.br/cnc/CavernasBW/RegioesBrasil\#>. Acesso em: 03 out. 2013. 
CORMIER, Nathaniel S.; PELLEGRINO, Paulo Renato Mesquita. Infraestrutura verde: uma estratégia paisagística para a água urbana. Paisagem Ambiente, São Paulo, n. 25, p.125-142, 2008.

FRANCO, Maria de Assunção Ribeiro. Infraestrutura verde em São Paulo: o caso do Corredor Verde Ibirapuera-Villa Lobos. Labverde, São Paulo, n. 1, p.134-154, out. 2010.

Infra-estrutura verde para as mudanças climáticas no C40.

Labverde, São Paulo, n. 6, p.219-235, jun. 2013.

GAVIOLLI, Rafael Julia. Estudo da Promoção Turística do Roteiro dos Bandeirantes. Turismo em Análise, São Paulo, v. 19, n. 3, p.405-423, dez. 2008.

HERZOG, Cecília Polacow; ROSA, Lourdes Zunino. Infraestrutura verde: Sustentabilidade e resiliência para a paisagem urbana. Labverde, São Paulo, n. 1, p.91-115, out. 2010.

MORAES, C.C.A.; GARCIA, G. \& Raimundo, S. Turismo no Alto-Médio Tietê: potencialidade e infra-estrutura, SEBRAE, São Paulo/INDER, Salto, SP. 2000.

OLIVEIRA, Fernando Vicente de; FERRÃO, André Munhoz de Argollo. Caracterização do Patrimônio Ambiental em Parques na Bacia Hidrográfica do Sorocaba - Médio Tietê: Cidades de Cabreúva. Itu, Salto e Porto Feliz, São Paulo. Oculum Ensaios, Campinas, n. 16, p.48-62, dez. 2012.

PNDU - PROGRAMA DAS NAÇÕES UNIDAS PARA O DESENVOLVIMENTO (Brasil). Ranking IDHM Municípios 2010: Salto. Disponível em: <http://www.pnud.org.br/atlas/ ranking/Ranking-IDHM-Municipios-2010.aspx>. Acesso em: 29 ago. 2013.

ROTA do Turismo - Revista VIU. Disponível em: <http://www.revistaviu.com.br/ noticias/rota-do-turismo/20040429000289_O_925>. Acesso em: 01 out. 2013.

ROTEIRO DOS BANDEIRANTES. Hotéis na região roteiro dos bandeirantes - SP. Disponível em: <http://www.roteirodosbandeirantes.com.br>. Acesso em: 01 out. 2013.

SÃO PAULO. Governo Do Estado De São Paulo. Sistema Ambiental Paulista. Área de Proteção Ambiental Cabreúva. Sobre a APA. Disponível em: <http://www.ambiente. sp.gov.br/apa-cabreuva/sobre-a-apa/>. Acesso em: 03 out. 2013. 
SEADE - FUNDAÇÃO SISTEMA ESTADUAL DE ANÁLISE DE DADOS (Brasil). Perfil Municipal: Salto. Disponível em: <http://www.seade.gov.br/produtos/perfil/ perfilMunEstado.php>. Acesso em: 29 ago. 2013.

SECRETARIA DE ENERGIA DO ESTADO DE SÃO PAULO. Energia Solar Paulista: Levantamento do Potencial. São Paulo: Governo do Estado de São Paulo, 2013.

SECRETARIA DO MEIO AMBIENTE DO GOVERNO DO ESTADO DE SÃO PAULO. O Programa. Disponível em: <http://www.ambiente.sp.gov.br/municipioverdeazul/ o-projeto/>. Acesso em: 06 out. 2013.

SUGUIMOTO, Flávia Tiemi. Paisagens do Médio Tietê: Formas de Uso e Apropriação de suas Águas para o Lazer. 2007. 143 f. Dissertação de Mestrado - FAU-USP, São Paulo, 2007.

WENDLER, Raquel Haber; MERLIN, José Roberto. O Sistema De Espaços Livres Em Salto: Possibilidade De Criação De Roteiro De Lazer Através Dos Parques. In: Encontro De Iniciação Científica Da Puc-Campinas, 2010, Campinas. Anais do XV Encontro de Iniciação Científica da PUC-Campinas. Campinas: 2010. v. 1, p. 1 - 7. Disponível em: <http://www.puc-campinas.edu.br/websist/portal/pesquisa/ic/pic2010/ resumos/2010924_145928_502021438_reserl.pdf>. Acesso em: 15 ago. 2013.

WWF-BRASIL. APA CABREÚVA. Disponível em: <http://observatorio.wwf.org.br/ unidades/mapa/421/>. Acesso em: 04 out. 2013.

WIKILOC: Eucalipto com subida da bica. trilha - Salto, São Paulo (Brazil) - GPS track. Disponível em: <http://pt. wikiloc.com/wikiloc/view.do?id=3798118>. Acesso em: 04 out. 2013.

WIKILOC: Trilhas Dos Desbravamento. trilha - Salto, São Paulo (Brazil)- GPS track. Disponível em: <http://pt.wikiloc.com/wikiloc/view.do?id=4794425>. Acesso em: 04 out. 2013.

WIKILOC: igrejinha abandonada. trilha - Salto, São Paulo (Brazil)- GPS track. Disponível em: <http://pt. wikiloc.com/wikiloc/view.do?id=5210599>. Acesso em: 04 out. 2013. 
WIKILOC: Pedal Itu - Fazenda Limoeiro 06/11/2011. trilha - Boa Chapeleira, São Paulo (Brazil) - GPS track. Disponível em: <http://pt. wikiloc.com/wikiloc/view.do?id=2195416>. Acesso em: 04 out. 2013.

WIKILOC: volta chacara sete quedas. trilha - Salto, São Paulo (Brazil) - GPS track. Disponível em: <http://pt.wikiloc.com/wikiloc/view.do?id=1430737>. Acesso em: 04 out. 2013. 